\title{
Teacher Education and Development in Africa: A Modern Perspective
}

\author{
Peter Wekesa Wamalwa \\ Turkana University College, \\ Lodwar, Kenya \\ Edwin Nyongesa Masibo \\ Kibabii University, \\ Bungoma, Kenya
}

\begin{abstract}
Teacher education programme is a critical component of education and the life of any society. It normally lays the very foundations of the society. It spurs and pushes the various aspects of development in the society through well-established culture and character of such a society. But for this programme of education to perform this development function efficiently it must be well designed, developed and constantly reformed and modernized so as to keep it abreast with the emerging issues both in education and society. This process is only possible through the conduct of regular studies in education and society to establish new developments and also facilitate the generation of relevant innovations to promote the quality of Teacher education programme. However, there is no evidence that such a process has ever been initiated and conducted in Teacher education programme since the inception of this programme in modern Africa. This paper is designed to explore the importance of Teacher education programme in modern Africa, the relationship between Teacher education programme and development in modern Africa, the roe of this programme in modern Africa, strategies of harnessing the programme for development in modern Africa and the challenges of the programme in modern Africa. This narrative is likely to shade light on the need of Teacher education programme in development in modern Africa and the role of innovative research in this process. Hence, set in motion the desired development in modern Africa.
\end{abstract}

Keywords: Role of Teacher Education; Challenges; Innovations and Development in Africa

\section{Introduction}

Teacher education programme is crucial in the development of the society. It is the vehicle for this process. Normally, Teacher education programme is the main basis for creation of the culture and character of the society that determines the nature and rate of development. In other words, this programmes determines the development agenda of the society. That is, it determines the political, social, economic and technological areas/aspects of the society. Through this programme, the desired designs and required strategies of realizing the aspired transformation of the society are conducted, hence 


\section{Journal of International Cooperation and Development \\ www.richtmann.org/journal \\ Vol 3, No 1, May 2020}

guaranteeing firm, accelerated and meaningful development in modern Africa. But for the teacher education programme to perform this development function efficiently in the society, the programme must be subjected to constant reforms so as to keep it abreast with emerging developments both in education and society. The required reforms in Teacher education programme are usually facilitated through the conduct of regular studies and well-intended government policies. The conducted studies not only establish the emerging issues in Teacher education programme but also provide opportunity for initiating and developing innovations in the programme that promote transformation of the society.

Generally, the manner the culture of the society is developed, perceived and managed has strong bearing a society sets and administers its development agenda. This is what makes culture an invaluable asset to any society. Culture comprises values that greatly cherished by the society. Some of these values form the basis of the envisaged development agenda of the society. Consequently, the tools (values and competencies) required for efficient administration of development have their origin in culture. But it is notable here that the culture of the society is normally the product of Teacher education programme (Kafu, 2010). Hence the nature, type and level of development in the society is a reflection of the designed and administered Teacher education programme (Lucas, 1968). In the foregoing discussion, three terms/concepts have kept on pomping up namely, Teacher education programme, modern Africa and development. Therefore, before presenting the out-line of this paper, it is necessary to clarify terms/concepts. In the context of this paper, Teacher education programme refers to the special, exclusive programme of education that deals with and/or focuses on all issues concerning/related to teaching profession. Among the issues of interest treated under this programme are Teacher preparation programme, teaching profession, emerging issues in Teacher education, the welfare of school teachers. In this respect, teacher education is highly regarded by all societies in the world and considered as the initiator, promoter and reservoir of the culture of the society.

However, modern Africa refers to the period from the late sixteenth century (exploration era) when Western Europeans came to Africa. The period when there was deliberate disruption of African cultures through introduction the so-called Western European civilization in Africa. It was a period of concerted effort to evangelize the African continent so as "to open it up" to civilized world. But development, on the other hand refers to the progress recorded by the society. In restricted sense, development is said to be prosperity of the society, living standards of the people in the society and/or observable changes in the cultures of the society. However, development of the society refers to various welfare issues affecting the society namely, political, social, economic and technological issues. Normally, these developments are observable, notable and of great interest to the society. After the definitions of the concepts of interest in this paper, it is now opportune to present the main out-line of the paper. 


\section{Journal of International Cooperation and Development \\ www.richtmann.org/journal \\ Vol 3, No 1, May 2020}

For convenience of presenting this paper, the discussion will be divided into six broad sections namely, importance of Teacher education programme and development in modern Africa contributions of the programme development in modern Africa, relationship between Teacher education programme and development in modern Africa, role of Teacher education programme in development in modern Africa, challenges of Teacher education programme in development in modern Africa, and strategies of harnessing Teacher education programme for development in modern Africa. This is the best and most enriching and engaging approach to tackling the issue under review.

\section{Importance of Teacher Education Programme and Development in Modern Africa}

The role of education in development in the society is well documented in literature (King, 1961; Lucas,1968; Jung,2004). In many societies, education is considered as the soft-ware, the power behind and/or "pusher" of the desired development (Ominde, 1965). But the main source of the energy for this development is Teacher education programme which initiates and develops the culture of the society that contains the main tools of developments. Some of these critical tools are the character of the society, competencies required for development and the inertia of the society to realize the set developments agenda. Teacher education is well placed to conduct this responsibility through the process of preparation and production of school teachers whose main role in the society is to transmit/disseminate the culture of the society (Ssenteza-Kajjubi, 1969). In this role, teachers act as agents of change in the society by transforming/modernizing it. This is the major importance of Teacher education programme in the society.

The other importance of Teacher education programme is that through the work of school teachers, the programme prepares individuals in the society to carry out diverse responsibilities. This is done by training these individuals in a variety of required competencies for development. Among these competencies is equipping the right attitudes, skills and knowledge for development. That is, preparing the society to participate fully in the established development agenda.

Teacher education programme also plays an important role by laying foundations of creating the desired society. It initiates, develops and nurtures the culture and character. Hence providing created society with the cherished values including those that facilitate the conduct of development agenda. If the culture of the society is pragmatic, transformative and adoptive, then the society will witness rapid development that promotes the welfare of the members of the society.

Teacher education programme is the face of the society. The manner this programme is organized and conducted determines the image of the society. In other words, the programme is the mirror of the society. That is whether this society is 


\section{Journal of International Cooperation and Development \\ www.richtmann.org/journal \\ Vol 3, No 1, May 2020}

progressive, modern, conservative, chaotic and/or stable. These are attributes that influence development in the society. Hence, Teacher education programme is a major cock in the wheel of development. Of greater importance is that Teacher education is practiced by all societies in the world (Sifuna, 1974; Wilkins, 1975). Its feature worldwide is that it prepares and produces school teachers and is the custodian of the culture of the society. In this function, the programme is a useful facility in universalizing and/or globalizing education, development and peoples of the world. Hence promoting the culture of peace, justice and understanding in the world (Kafu, 2014).

Specifically, Teacher education programme is the basis of development in the society. It prepares and supplies the society with the essential (school teachers) skilled man-power for development, through the established cultural practices including research work, the programme initiates and perfects the needed competencies for development and generates the creativity and innovations that drive the development agenda of the society. This is where the discussion on relationship between the Teacher education programme and development in the society is relevant (Sifuna and Indire, 1978; Watford, 2007).

\section{Relationship between Teacher Education Programme and Development in Modern Africa}

This refers to what connects Teacher education programme and development in modern Africa. In other words what is common between these two processes or features in modern Kenyan society. Generally, the relationship between Teacher education programme and development is symbiotic. That is the processes influence each other. The former generates and provides the energy for the development of the society while the latter provides investment for the developments, capacity-building and administration of the Teacher education programme.

Besides the above, Teacher education programme and development are competence-based processes. They require and depend on the developed attitudes, knowledge and skills in the society. These are essential tools needed for efficient administration of the two processes. Normally, they are specialized competencies specific to these processes and derived from the culture of the society. Further, the Teacher education programme and development are culture-based processes. They are based on and derived from the culture of the society. In effect the two processes are a reflection and the mirror as it were, of the cultural practices and the character of the society. More often than not, the two features are value-based which are derivatives of the culture of the society.

Generally, Teacher education programme and development need heavy investments in terms of resources, skill and labour. In addition, they need efficient administrative, technical and logistical support for them to function well. In other words 


\section{Journal of International Cooperation and Development \\ www.richtmann.org/journal \\ Vol 3, No 1, May 2020}

the two processes are skill, resource and labour intensive. Therefore, there is need for proper planning and organization in order to cater for these requirements (Ochitti, 1992). In order to do this efficiently, there is need to establish the emerging developments in these two processes. Some of these emerging issues are the management systems and management systems analysis and technological advancements in the world that have generated new developments that globalization process.

Finally, Teacher education programme and development as processes have great influence on the transformation of the society. They are the genesis of modernization in any society. Through the exposures, experiences and interactions these two processes adopt to, adapt and introduce new models of development in the society.

The above discourse becons the question, "what is the role of Teacher education programme in development in modern Africa? Hence, the discussion that follows focuses on the role of the two processes in this continent.

\section{Role of Teacher Education Programme in Development in Modern Africa}

This refers to the place of Teacher education programme in the development of modern Africa. That is, what this programme has done or contributed to the development of the African continent since its inception in the sixteenth century.

The role of Teacher education programme in the development of modern Africa cannot be under-estimated. Modern Africa is what it is to-day because of this programme (Sifuna and Indire, 1978; Bokongo, 1972). Its role in the development of modern was specified by the mission/purpose of the programme which was to "train school teachers for the school education system". Specifically, the role of Teacher education programme in development in modern Africa is multi-variate.

The initial role of Teacher education programme in modern Africa is articulated by the Consolata and Mill Hill missionaries in Kenya. According to these organizations "Teacher Training Centres" were to "train school teachers for their Mission and Bush schools" (Chronicles of Education in Kenya, 1924). The purpose of this programme was at the time, to prepare and produce teachers who to evangelize, transform and introduce western European culture to Africa. However, this role was to be expanded after the African countries gained independence in nineteen sixties (O.A.U, 1963; UNESCO, 1973). The new role for school teachers was to prepare and produce skilled man-power to spear-head the emerging developments in Africa. Apart from teaching, school teachers were expected to serve as "agents of change" in their society. Hence facilitating the transformation of the African continent from the "backward/dark/primitive" state to the modern region in the world

Teacher education programme is also regarded as a catalyst in development of the society. It initiates the culture for the society to be created with a variety of values that 


\section{Journal of International Cooperation and Development \\ www.richtmann.org/journal \\ Vol 3, No 1, May 2020}

are meant to boost development in the society. The values are the instruments that are used to fire all sorts of development in the society-political, social, economic, technological, innovations, ......etc. That is the programme is the steam/driving force behind any designed development programmes in the society. This is because Teacher education programme deals with teaching profession and other attendant issues that serve as the basis for creating and sustaining innovations in the society.

The programme develops, provides and sustains the quality of development in the society by ensuring there is constant supply of skilled man-power. Ominde (1965) and Karanja (1978) appreciate this fact by calling for promoting the quality of Teacher education programme in Kenya. It is an established fact, as demonstrated in the Tigers of Asia" region, the quality of trained school teachers are triggers and boosters of development in the society (Lucas, 1968; 2007).

Related to the above discussion, Teacher education programme is the measure/barameter of determining the level, rate and nature of development in the society. It is usually used to determine these features of development $t$ in the society. This is so because, through Teacher Preparation programme, school teachers are equipped with competencies for developing talents of the learning and determining the trends) of development in the society. In this way, the school teachers and, by extension, Teacher education programme, serve as, the best guides in the development of the society (King, 1961; Bosire,1995; Ringa, 1994).

Following this discussion on the role of Teacher education programme in the development of modern Africa, it is now possible to localize this to the Kenyan experience. In the case of Kenya, the role of this programme has been, since colonial era, to "train" school teachers, prepare and provide skilled man-power for development in the country, serve as an agent of transformation in Kenya, promote, sustain and enhance development in Kenya and, during colonial period to promote the European cultures in the name of civilization. These are aspects of contributions of this programme in modern Africa which are discussed in the next section of the paper.

\section{Contributions of Teacher Education Programme to Development in Modern Africa}

This section of the paper deals with the benefits of Teacher education programme in terms of development to modern Africa and specifically modern Kenya. In other words the gains modern Africa has drawn from this programme. That is, the value-addition of the programme to development in modern Africa and, especially, Kenya. Generally, the present discussion refers to the influence of Teacher education programme on development in modern Africa or simply put, the out-comes/ results of administering this programme in this continent since the colonial era.

In order to discuss the contributions of Teacher education programmes to development in modern africa adequately, it is necessary to re-state the 


\section{Journal of International Cooperation and Development \\ www.richtmann.org/journal \\ Vol 3, No 1, May 2020}

mission/purpose/objective of this programme in Africa. Initially, "Teacher Training" programmewas developed in modern africa to "train" school teachers. This mission/purpose/objective of the programme has remained so to the present. To many people in africa "Teacher Training" programme which is to-day referred to as Teacher Preparation programme is equated with preparation of school teachers for the school systems. The other collateral roles of this programme do not cross the minds of many people in this continent. Therefore, there is need to examine some of the incidental or is it accidental contributions of the Teacher education programme in modern Africa. These contributions of this may be broadly discussed under two categories namely, positive and negative contributions.

The positive contributions of the Teacher education programme in moden Africa and especially Kenya has been the preparation and production of school teachers who have served this continent with dedication in various sectors other than teaching profession. These individuals have served in the civil service, security agencies, private sectors and as role models in various sectors of the economy. This preparation of the school teachers in both public and private sectors in African countries has facilitated the setting in motion the development agenda of many an African country.

Besides, Teacher education programme laid the foundation of preparation and production of skilled man-power needed for development in modern Africa. Ominde (1965) and Okore (2009) recognized the role of education and, by extension, Teacher education programme in this function. Through the teaching force various talents have been $\mathrm{d} 3 \mathrm{ev}$ eloped and utilized in the development of various aspects of life in Africa. As Mazrui (1984) points out development in modern Africa can hardly take off without proper engagement of teacher. This is an echo of the views of Lucas (1968) and Karanja (1978) who feel Teacher education programme is vital to development in modern Africa to-day.

Further, since colonial era, Teacher education programme was charged with the responsibility of creating the desired society. Consequently, prospective teachers were prepared in ethics of teaching and ethics of Teaching profession which they were expected to use when teaching school children/learners. These ethics were intended to prepare the latter for their role in the society as patriots and good citizens in their respective countries.

In addition, Teacher education programme has promoted and sustained development in political, social, economic and technological spheres in modern Africa. Through this programme political leaders, renowned scholars, entrepreunurs, farmers of high standards have been created and established in Africa. This development has transformed the african continent from "Dark" continent to a modern continent (Okotbitek, 1970). Hence globalizing/internalizing the African continent.

The above and many others not mentioned because of time and space are the collateral benefits/contributions of Teacher education programme to development in 


\section{Journal of International Cooperation and Development \\ www.richtmann.org/journal \\ Vol 3, No 1, May 2020}

modern Africa including Kenya. However, there are negative contributions of this programme to development in modern Africa. This is the dark side of the Teacher education programme with respect to political, social, economic and technological development in modern Africa. In effect this is what constitutes the short-comings of this programme in the development of modern Africa. Some of the negative contributions of the programme include those presented herein below.

From the inception of formal Western European type of Teacher Preparation in Germany and later in Lancaster in England in the sixteenth century, the preparation of school teachers emphasized pedagogy-"how to teach" and nothing else. The interest on the equipping prospective teachers with the required competencies of teaching and not any other critical collateral issues to teaching profession is what this paper regards as the dark side of teacher education.

The prepared and produced school teachers were encouraged to be authoritarian while teaching. They were taught to apply the age-old adage that says (save the cane spoil the child". Consequently, these teachers were inspired to be brutal to learners. The consequence of this was to turn classrooms into "butchers" and "Lashing" Venues. This practice in teaching was later to manifest itself later when the products of this brutal school education system gained authority as political leaders, army officers and/or police officials and civil servants. They exacted, in equal measures, the brutality they went through on innocent civilians especially in the period of the sixties (1960's) and eighties (1980's) when political and military leaders embarked on the mission of massacring the people they were supposed to rule. Their actions were a true reflection of the experiences these leaders went through during their school days.

The other negative contribution of the Teacher education programme was the preparation and production of school teachers who were not responsible in out-look, individuals who were not critical enough and not innovative in their teaching and related duties. These teachers were always expected to take instructions from the authority and not make independent decisions. This is the behavior this crop of teachers carried to their classrooms when teaching. The learners were supposed to be recipients of what the teacher was to teach. However, this bad, unproductive teaching model of preparing and producing citizens characterized by "dependence syndrome" Individuals who lack the ability and capacity to generate ideas that can be used to develop modern Africa and always waiting to be supported/helped from whichever quarter. This is what has underdeveloped the African continent.

In addition, the conservative nature and limited in scope of the Teacher education curriculum has undermined the preparation of prospective teachers in creativity and innovativeness which are the major tools in development. These teachers, therefore, have not been able to develop and nurture these critical attributes in learners that they would have used to explore the existing potential for development in modern Africa. The main cause of this scenario is that school teachers have continued to be trained in 


\section{Journal of International Cooperation and Development \\ www.richtmann.org/journal \\ Vol 3, No 1, May 2020}

conservative/traditional models like teacher-centred approach instead of innovative instructional technologies like independent studies, learner centred, open and distance learning models. This has undermined the capacity of these school teachers to create new ideas and explore the teaching environment for opportunities to advance the development of modern Africa as called for by the Organization of African Unity (O.A.U.) in 1963 and Karanja (1978). This situation is demonstrated the backwardness of technological development in modern Africa.

However, the most serious negative contribution of Teacher education programme to development in modern Africa and especially in Kenya has been the creation of the elitist society. This is a feature in the society where only a few are privileged, can access certain status and enjoy the available opportunities available in the society. This sad situation can be observed in the conduct of political leadership, social strata, and the distribution of economic opportunities in the society. Only a few privileged individuals are able to access and enjoy these opportunities. Education opportunities are designed to benefit these few.

Finally, the existence of conservative tendencies in development in modern Africa which is heavily culture-based is a direct reflection of the nature and design of Teacher education programme in modern Africa. On reflection, this demonstrates lack of reforms in this programme since the colonial era which could have spurred pragmatic approach to designing and administering development in modern Africa. As already hinted elsewhere in this paper, without creativity and innovativeness in the African society, pragmatic development is a far cry in modern Africa. The question is how does modern Africa came out of the present messy situation regarding development? Strategies of harnessing the Potential of Teacher Education programme for development in modern Africa is an attempt to do this.

\section{Strategies of Harnessing the Potential of Teacher Education Programme for Development in Modern Africa}

There are many ways modern Africa can use to redeem itself from the present awkward state of development in comparison to other regions of the world. The strategies that can be employed to achieve the desired development include those proposed by Langlands (1970) in his inaugural lecture presentation in Makerere University College in 1970. However, the following strategies are proposed by this paper when attempting to utilize Teacher education programme in the development of modern Africa.

The first strategy is to reform Teacher education programme in modern Africa by broadening the existing Teacher education curriculum to include study areas that lead themselves to development of creativity and innovativeness in prospective teachers. In addition, the programme should be professionalized. Only trained and qualified persons in Teacher education should be engaged in Teacher Preparation programme. These are 


\section{Journal of International Cooperation and Development \\ www.richtmann.org/journal \\ Vol 3, No 1, May 2020}

individuals who are familiar with and understand the Teacher education programme, its purpose, objectives and mission in development in modern Africa. These reforms in the programme will make it relevant to the needs of modern Africa and, therefore, facilitate the desired development on the continent.

The second strategy is to design and conduct needs assessments/situational analyses in Teacher education programme and the society to determine the existing conditions and/or needs in these two areas. With the availability of relevant information, it is possible to design and develop relevant Teacher education curriculum to address the needs of modern Africa, relate the administration of the Teacher education programme to the developmental needs of modern Africa. Hence facilitating rapid, well co-ordinated and competitive development in this continent as aspired by Karanja (1978).

The third critical strategy of harnessing Teacher education programme for development in modern Africa is to harmonize this programme and the development agenda of the African continent. This strategy will ensure the Teacher education programme operates at tandem with the development aspirations in modern Africa. The consequence of this development is increased collaboration between Teacher education programme management teams and national government/state authority. This approach will guarantee coherent development in modern Africa.

Apart from conducting reforms in Teacher education programme affecting the scope of its curriculum and management, there is urgent need to modernize this programme. The programme should adopt to and adapt emerging modern technologies of teaching and training human resources to facilitate the introduction and use new models of instruction. Among the most current technologies needed in Teacher education programme is computerization. This will in turn facilitate technologization of the programme (Kafu, 2015). Hence creating opportunity for globalization of both the programme and development in modern Africa.

Finally, though not least, there is need to invest adequately in Teacher education for the purpose of its efficient administration, modernization and development of relevant facilities and resources for managing it. Investments will not only promote the quality of the programme but also attract talented individuals to join the programme and contribute to the development of modern. These investments are wide ranging but not limited to funds, expertise, technical and logistical support that can be used to prepare and produce competent school teachers with ability and capacity to turn around development in modern Africa.

It would be wishful thinking to assume that what has been discussed above does not have issues. Generally, Teacher education programme and development in modern Africa has many challenges as the discussion that follows demonstrates. 


\section{Journal of International Cooperation and Development \\ www.richtmann.org/journal \\ Vol 3, No 1, May 2020}

\section{Challenges of Teacher Education Programme in Development in Modern Africa}

Challenges of Teacher education programme in development in modern Africa are emerging issues in this programme and society and the potential problems facing this problems. There are many challenges of this programme in development in modern Africa but for the purpose of the present narrative, only six have been identified for discussion.

The first challenge has to do with conservative nature of the Teacher education programme. There have been limited reforms in the programme since its inception in Western Europe in the sixteenth $\left(16^{\text {th }} \mathrm{C}\right.$.) century. The curriculum is restricted heavily to training prospective teachers in pedagogy with little attention to other supporting areas. The programme has continued engaging amateurs to manage it in modern Africa. Most of the staff currently engaged in Teacher preparation programmes are drawn from the school system who were trained to teach school subjects and not prepare prospective teachers.

The second challenge is associated with investment in the Teacher education programme. From the colonial era especially in Kenya, the state had little interest in this programme. It was largely left to the missionaries and other interested parties in education in modern Africa. The same practice has been continued well after independence from colonial powers in the sixties (1960's). Most independent countries of modern Africa have placed greater emphasis on Primary/elementary, secondary and university education sectors and NOT Teacher education programme. Therefore, this programme has tended to suffer from neglect and deliberate under-development from the state. Consequently, the programme has not played its rightful role in development of modern Africa.

The third challenge which is closely related to the second challenge above is the established negative attitude towards Teacher education programme during postindependence modern Africa. The present society in Africa has low regard of this programme because of a number of emerging issues among which is the existing misconception of the role, function and mission of the programme in development in modern Africa. The other emerging issue is the relatively poor schemes of service for teachers. Their remunerations and other packages are not comparable to those extended to professionals from other lucrative professions. However, countries across modern Africa have made efforts to improve terms and conditions of service for school teachers though not good enough. The other issues that contribute to these negative attitudes towards the programme are its conservative nature and the widespread failure to recruit trained and qualified professionals in teaching.

The fourth challenge is related to historical factors associated with the development of the programme in modern Africa. As indicated above, during colonial era the development of Teacher education programme was left in the private hands- 


\section{Journal of International Cooperation and Development \\ www.richtmann.org/journal \\ Vol 3, No 1, May 2020}

mainly Christian missionaries. Colonial governments came in rather too late when they realized they were being eclipsed in this sector by private practitioners. Hence, these governments lacked experience and expertise to manage this programme as the most professional sector of education. The problems currently experienced in managing this programmes, and they are many, were inherited from colonial administration.

The fifth challenge is related to what has already been presented above- the structural design of Teacher education programme as practiced in modern Africa. The administration of the programme, especially the structure of Teacher education curriculum has challenges. There is an over-dose of professional studies courses, which is essential for preparing professional school teachers, at the expense of broadened content areas which are a requirement for preparing a modern school teacher. Besides, the programme is conservative in nature, narrow in scope and rigid to adopt to adapt emerging developments in education, and especially Teacher education programme, and the society. These are the features that have made the programme appear irrelevant to the needs of the modern world and condemned as non-performing sector of education.

The last though not least challenge concerns equipping Teacher preparation institutions to facilitate their preparation and production of competent school teachers who can promote development in modern africa. Generally, these institutions are greatly under-funded across the continent (UNESCO, 1978). This situation has resulted in the development of poor and, sometimes, irrelevant facilities and resources for managing the programme. More often than not these items are limited in supply for the rapidly expanded programme and poorly maintained by the institutions for lack of funds and ignorance.

However, with good will, proper management cueness and determination from mother state/education authorities and other stake-holders in education, the discussed and presented challenges are manageable. If modern Africa, especially Kenya, has to competitively develop these issues must be properly addressed.

\section{Conclusion}

In this paper, Teacher education programme has been presented as a significant programme of education. Its role and contributions to development in modern Africa, and especially in Kenya has been well out-lined. Though a few challenges to the development and administration of the programme for development in modern Africa have been identified and briefly discussed, these are manageable as demonstrated by the presentation on the strategies of harnessing the potential of the programme for development in modern Africa. 


\section{Journal of International Cooperation and Development}

www.richtmann.org/journal

Vol 3, No 1, May 2020

\section{References}

Bosire, E. S (1995). Proposals for the Improvement of Training Teachers of English for Primary Schools in Kenya. Master of Philosophy Thesis. Eldoret Moi Unversity.

Kafu, P. A (2012). Teacher Education, the Incubator of Science and technology for Development in Africa'. African Journal of Education, Science and Technology Vol. 1 No. 1 ISSN 2309-9240

Kajjubi, Ssenteza (1969). 'Fashions in Education for Development in East Africa' Kampala

Karanja, J. (1978). Development of Quality Education in Kenya in this Decade and Beyond: The Case of Teacher training Programme'. Daily Nation July Issue.

Kings, S. (1961). Education, Society and Development in Africa.

Lucas, J. (1968). 'Development of Teacher Education in Africa'. Kampala.

Ominde, J. (1965). Education Commission Report on Reforms in Education in Kenya.

Ringa, K. (1994). 'Organization of Management of Teaching Practice in Kenya.' 